\title{
TWOMEY EFFECT IN SUBTROPICAL STRATOCUMULUS CLOUDS FROM UV DEPOLARIZATION LIDAR
}

\author{
Martin de Graaf $^{1,2, *}$, Jessica Brown ${ }^{3}$ and David Donovan ${ }^{1}$
}

\author{
${ }^{1}$ Royal Netherlands Meteorological Institute (KNMI), Utrechtseweg 297, 3731 GA De Bilt, The \\ Netherlands*martin.de.graaf@knmi.nl \\ ${ }^{2}$ TU Delft, Geoscience and Remote Sensing (GRS), Stevinweg 1, 2628 BN Delft, The Netherlands \\ m.degraaf@tudelft.nl \\ ${ }^{3}$ Wageningen University \& Research, Droevendaalsesteeg 4, 6708 PB Wageningen, The \\ Netherlands
}

\begin{abstract}
Marine stratocumulus clouds are important climate regulators, reflecting sunlight over a dark ocean background. A UV-depolarization lidar on Ascension, a small remote island in the south Atlantic, measured cloud droplet sizes and number concentration using an inversion method based on Monte Carlo (MC) modelling of multiple scattering in idealised semiadiabatic clouds. The droplet size and number concentration were modulated due to smoke from the African continent, measured by the same instrument.
\end{abstract}

\section{INTRODUCTION}

The interaction between clouds and aerosols, and the resulting impact on radiative forcing is one of the most uncertain mechanisms in the global climate system. To gain a better understanding of these important interactions a number of international campaigns have taken place in the southeastern Atlantic region in 2016. This region is characterised by a consistent layer of marine boundary layer stratocumulus clouds, capped by a temperature inversion created by widespread subsidence. Large biomass burning events in the southern African dry season lead to high concentrations of aerosols being advected across and above these cloud layers. This region has often been described as a 'natural laboratory' for examining cloud and aerosol interactions. Here we present the first results from the Ascension Island Initiative (ASCII) campaign. The aim of the ASCII campaign was to identify whether the microphysical properties of marine stratocumulus clouds altered with the presence of aerosols. To achieve this, a depolarisation UV lidar was set up on Ascension in September 2016. This month was selected as the burning season in southern Africa. It was also selected to coincide with a period of intensive observations from a number of other international campaigns including LASIC, CLARIFY and NASA-ORACLES, based in Walvis Bay, all of which also focused on understanding and investigating the interaction of biomass burning smoke and clouds in the southeast Atlantic region.

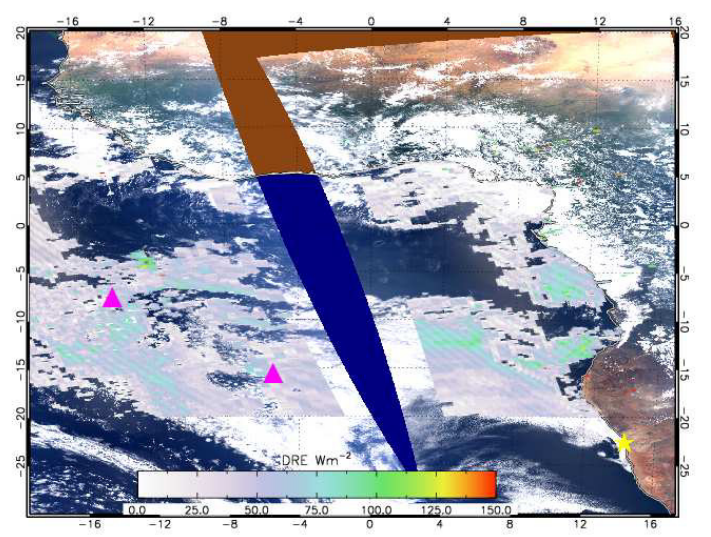

Figure 1: Aerosol Direct Radiative Effect in $\mathrm{Wm}^{-2}$ over stratocumulus clouds in the Atlantic Ocean on 24 September 2016, derived from colocated OMI and MODIS reflectance measurements. The pink triangles indicate the locations of Ascension Island (left) and St. Helena (right). The yellow star indicates Walvis Bay in Namibia. 
Ascension Island is a remote, volcanic island located at $8^{\circ} \mathrm{S} ; 14^{\circ} \mathrm{W}, 1600 \mathrm{~km}$ from Africa and $2250 \mathrm{~km}$ off the coast of Brazil, see Figure 1. The typical clouds found in subtropical marine regions, such as around Ascension Island, are low lying bands of stratocumulus capping the boundary layer and are typically found between $1-1.5 \mathrm{~km}$. These marine stratocumulus clouds are very important for the global climate, as they have a high albedo compared to the dark ocean over which they occur and reflect around $30 \%$ of the incoming solar radiation[1]. An estimated $4 \%$ increase in their cover could offset the warming due to a doubling of $\mathrm{CO}_{2}$ [2]. There are many ways in which aerosols interact with clouds. In this paper we focus on the first aerosol indirect effect (Twomey effect).

\section{METHODOLOGY}

The ASCII campaign was conducted on Ascension Island from 1-30 September 2016, with the aim to investigate the effect of biomass burning aerosols on cloud microphysical properties using a ground-based UV depolarisation lidar. Observations from the lidar were processed using an inversion method which produces estimates of cloud microphysical properties such as the effective radius and cloud droplet number density. This new inversion method is based on Monte Carlo modelling of multiple scattering within idealised semiadiabatic clouds[3]. The method utilizes the propensity of light to become depolarized when it undergoes multiple scattering within a liquid water cloud. The backscattered radiation from spherically symmetrical and uniform elements such as liquid cloud droplets retains the polarization of the incident light under single scattering. However, the returning light will be partially depolarized due to multiple scattering within liquid water clouds. The inversion method used here is based on a simple cloudbase representation, with a linear liquid water
Table 1: Range of parameters used in the MC simulations

\begin{tabular}{|l|l|}
\hline Parameters & Values \\
\hline Cloud base $[\mathrm{km}]$ & $0.5,1.0,2.0,4.0$ \\
FOV [mrad] & $0.5,1.0,2.0,4.0$ \\
$R_{\text {eff }}$ & $2.0,2.6,3.3,4.3,5.6$, \\
& $7.2,9.3,12.0$ \\
$\Gamma_{l}$ & $0.1,0.2,0.4,0.6,0.8,1.0$ \\
& $1.2,1.4,1.6,1.8,2.0$ \\
\hline
\end{tabular}

content lapse rate $\Gamma_{l}$ as well as a constant cloud droplet number density $\mathrm{N}_{\mathrm{c}}$. As the liquid water content (LWC) increases with height while the number density remains constant, the effective radius $R_{\text {eff }}$ is increased with height. The extinction coefficient $\alpha$ also increases with height. The droplet size distribution used is a singlemode modified-gamma distribution. This simple but representative liquid water cloud model enables the computation of multiple scattering inside the cloud using Monte Carlo modelling. The Earth Clouds and Aerosols Radiation Explorer (EarthCARE) simulator (ECSIM) lidarspecific MC forward model was used to compute LookUp Tables (LUTs) for various values of cloud-base height, lidar field of view (FOV), $R_{\text {eff }}$ and $\Gamma_{l}$, see Table 1 for the values used.

\section{RESULTS}

During the campaign, overcast skies with light drizzle was common. The average surface temperature was $21.32^{\circ} \mathrm{C}$, with an average precipitation rate of $0.11 \mathrm{~mm} \mathrm{hr}^{-1}$ and an eastsoutheasterly wind direction. Generally a well defined stratocumulus deck was present at around 1 to $1.5 \mathrm{~km}$, as well as a persistent temperature inversion. Due to high solar radiance and the high position of the sun during the day there was a large amount of solar background noise, meaning aerosol signals were generally only visible during the night. Aerosols were visible on 19 out of the 25 days observed and 


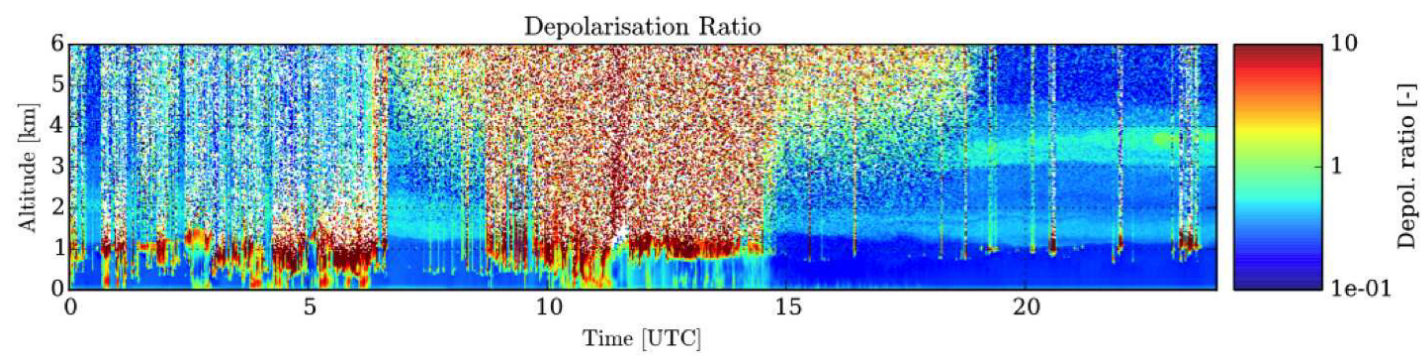

Figure 2: Depolaristion measurement from the UV depol lidar on Ascension Island on 20 September 2016, showing broken clouds at the top of the boundary layer, with two aerosol layers, one near the cloud bottom and one in the free troposphere (around $4 \mathrm{~km}$ ).

occurred between heights of 1.5 to $4.5 \mathrm{~km}$.

Figure 2 shows an example measurement from the UV depolarisation lidar on 20 September 2016. The depolarisation signal shows broken clouds during the morning and afternoon, and clear skies in the evening and night. In the clear sky parts, several aerosol layer are visible.

During overcast periods, cloud parameters were retrieved from the depolarisation measurements. An example is shown in Figure 3 for 22 September 2016. The cloud droplet number density and effective radius were retrieved at a height of $100 \mathrm{~m}$ above the cloud base. To identify the effects of smoke on cloud properties, each day was classified as either a clean, mixed

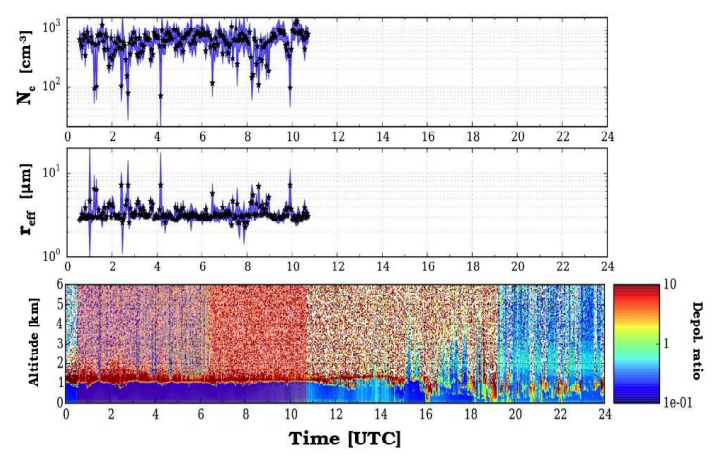

Figure 3: Inversion results for the $22^{\text {nd }}$ of September. This is an example of an ideal period to invert, with a very well-defined ATB peak and an absence of below cloud aerosols or drizzle. or separated case. Clean cases indicates days when no aerosols are visible while mixed cases were when aerosols are visible directly above the peak attenuated backscatter. This indicates that aerosols may have been mixing with the cloud layer. Separated cases were days when aerosols are seen in a layer which is vertically separated from the cloud layer below it. The majority of days fall in the mixed category, with dramatically fewer days falling under the clean and separated cases. The cloud droplet number density and effective radii were averaged for each case. Generally there is a clear differentiation in the mean values of each inversion product between each of the three cases. The $\mathrm{R}_{\text {eff }}(100)$ ranged between 3.4 to $4.2 \mu \mathrm{m}$, with the highest value occurring for the clean case, see Figure 4. Both the mixed and separated cases had similar mean values for $\mathrm{R}_{\mathrm{eff}}(100)$. The $\mathrm{N}_{\mathrm{c}}$ peaked in the mixed case at $550 \mathrm{~cm}^{-3}$ with the smallest value occurring in the clean case.

\section{CONCLUSIONS}

During the ASCII campaign the majority of days fell under the mixed case with aerosol layers being visible directly about the peak attenuated backscatter. This suggests that the aerosols may be mixed into the cloud layer. The presence of aerosols at heights of less than $2 \mathrm{~km}$ supports the idea that the widespread 

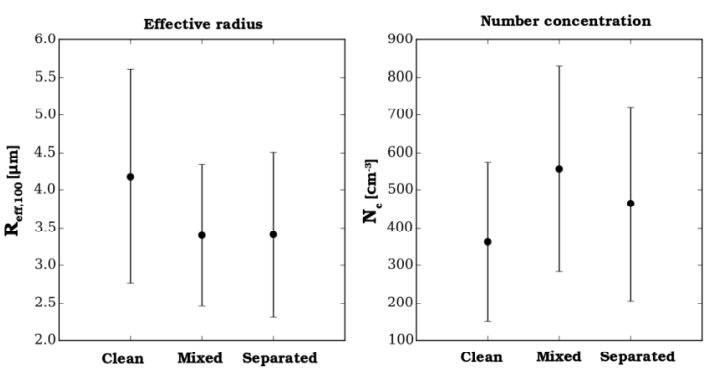

Figure 4: Average cloud droplet effective radii and number concentrations at $100 \mathrm{~m}$ above cloud base for the different identified cases: clean (no smoke), mixed (aerosols around cloud base) and separated (aerosols at high altitude).

subsidence occurring across the southeastern Atlantic region mixes smoke downwards as it moves away from the African coast at high altitudes. The mixed cases show an increased cloud droplet number concentration as well as a smaller effective radius at $100 \mathrm{~m}$ above cloud base. This suggests a cloud aerosol indirect effect, with aerosol particles acting as $\mathrm{CCN}$. The $\mathrm{N}_{\mathrm{c}}$ increased by $200 \mathrm{~cm}^{-3}$ from clean cases while the $\mathrm{R}_{\mathrm{eff}}(100)$ dropped by almost $1 \mu \mathrm{m}$. The separated cases sit in between the clean and mixed for $\mathrm{R}_{\mathrm{eff}}(100)$ and $\mathrm{N}_{\mathrm{c}}$. This may be explained by slight mixing of smoke from the separated layer into the clouds, which is not clearly seen in the lidar. In a previous study over the southeastern Atlantic a drop in cloud droplet effective radius of $30 \%$ was found [4], similar to what is observed here (a decrease by $20 \%$ ). A key difference here is that in that study satellite observations (cloud top) were examined, while the inversion method here focuses on cloud properties near the cloud base. In addition, other factors which may have lead to this difference between cases, such as varying meteorological conditions, have not been examined in this study. Possible meteorological changes are currently being investigated to extract a definite conclusion about the Twomey affect over Ascension Island due to smoke incursions.

\section{ACKNOWLEDGEMENTS}

This campaign was funded by the Koninklijke Hollandsche Maatschappij der Wetenschappen (KHMW). Karolina Sarna is gratefully acknowledged for her initial involvement in the project.

\section{References}

[1] Bennartz, R., 2007, Global assessment of marine boundary layer cloud droplet number concentration from satellite. Journal of Geophysical Research 112 (D2), D02201.

[2] Albrecht, B. A., D. A. Randall, S. Nicholls, B. A. Albrecht, D. A. Randall, and S. Nicholls, 1988, Observations of Marine Stratocumulus Clouds During FIRE. Bulletin of the American Meteorological Society 69 (6), 618-626.

[3] Donovan, D. P., H. Klein Baltink, J. S. Henzing, S. R. de Roode, and A. P. Siebesma, 2015, A depolarisation lidar-based method for the determination of liquid-cloud microphysical properties. Atmospheric Measurement Techniques 8 (1), 237-266.

[4] Costantino, L. and F.-M. Bréon, 2013, Aerosol indirect effect on warm clouds over South-East Atlantic, from co-located MODIS and CALIPSO observations. Atmospheric Chemistry and Physics 13 (1), 69-88. 